Edu Consilium: Jurnal BK Pendidikan Islam

Vol. 3, No. 1, 2022, hlm. 79-88

DOI: $10.19105 /$ ec.v1i1.1808

ISSN 2503-3417 (online)

ISSN 2548-4311 (cetak)

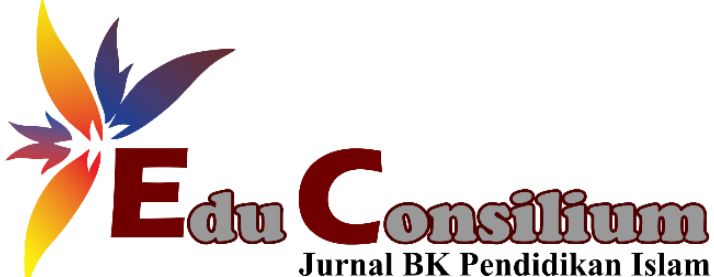

\title{
PENGARUH PERSON ORGANIZATION FIT TERHADAP KOMITMEN ORGANISASI
}

\author{
${ }^{1}$ Hardani Dwi Jayanti \\ ${ }^{1}$ Program Studi Magister Psikologi, Universitas Mercubuana Yogyakarta, Indonesia \\ hardadwij@gmail.com
}

\begin{tabular}{ll}
\hline & Abstract \\
\hline Keywords: & Organizational commitment is defined as the degree to which employees have confidence in \\
Person & and accept organizational goals or organizational regulations, and are willing to stay with \\
organization & the company or leave the company. The cause of the commitment that is not owned by this \\
fit, & individual will lead to the problem of leaving employees and the side of social organization \\
Employee & that provides discomfort. The impact of this commitment and suitable person organizatior \\
commitment. & provides a positive side for the company in terms of organizational culture. The purpose of \\
this organizational commitment is to find out the factors that influence the organization & according to employees in terms of the employee's organizational culture with the company \\
& So that it will reduce the problems that exist in the company because of individual \\
& incompatibility with the company. The benefits of research on a more comprehensive study \\
& of organizational commitment and people are expected to provide more comprehensive \\
knowledge for science.
\end{tabular}

Kata Kunci:
Person Organization
Fit;

Fit;

Komitmen organisasi.

\begin{abstract}
Abstrak
Komitmen organisasi didefinisikan sebagai tingkat karyawan sampai dimana karyav mempunyai keyakinan dan menerima tujuan organisasi ataupun peraturan organisasi, si berkeinginan untuk tinggal menetap diperusahaan atau meninggalkan perusahaan. Penyel komitmen yang tidak dimiliki oleh individu ini akan menimbulkan permasalahan kel masuknya karyawan dan sisi sosial organisasi memberikan ketidaknyaman. Dampak c komitmen dan person organization fit ini memberikan sisi positif untuk perusahaan dalam budaya organisasi. Tujuan dari komitmen oraganisasi ini ialah untuk mengetahui faktor-fal yang mempengaruhi person organization fit karyawan dilihat dari sisi kesesuaian bud organisasi karyawan dengan perusahaan. Sehingga akan mengurangi permasalahan yang diperusahaan karena ketidaksesuaian individu dengan perusahaan. Manfaat penelitian terhar kajian yang lebih komprehensif mengenai komitmen organisasi dan person organization yang diharapkan dapat memberikan keilmuan yang lebih komperhensif bagi keilmı psikologi.
\end{abstract}

CEdu Consilium: Jurnal Bimbingan dan Konseling Pendidikan Islam

Institut Agama Islam Negeri Madura, Indonesia 


\section{PENDAHULUAN}

Daya manusia merupakan aset yang sangat berharga untuk perusahaan. Dengan persaingan bisnis yang semakin ketat memberikan dampak terhadap peningkatan pencarian karyawan yang bertalenta untuk memberikan kontribusi. Namun mempertahankan karyawan merupakan tantangan untuk perusahaan. Fenomena keluar masuknya karyawan berpotensi menimbulkan kerugian bagi perusahaan. Kerugian perusahaan disebabkan karena timbulnya pembengkakan biaya rekrutmen. Perusahaan juga harus mampu mencari pengganti karyawan keluar tersebut dengan karyawan baru dengan talenta yang tidak jauh berbeda.

Tantangan yang dihadapi organisasi ialah menarik, menahan dan mengembangkan Sumber Daya Manusia. Salah satu kunci keberhasilan organisasi era globalisasi saat ini ialah adanya kesesuaian antara nilai individu dengan nilai organisasi sehingga akan menjadi sinergitas yang akan memberikan dampak positif baik dalam perencanaan maupun, implementasi tugas dan tanggungjawab karyawan untuk mencapai visi, misi dan tujuan organisasi. Nilai individu dari organisasi juga seharusnya sejalan dengan nilai-nilai yang ada di organisasi perusahaan yang sehat. Agar nilai individu dan organisasi itu selaras atau sesuai dengan perusahaan. Perubahan situasi harus mampu diterima oleh karyawan. Dari perubahan nilai dan tujuan akan menuntut karyawan untuk bisa menyesuaikan diri dengan kondisi yang ada. Sehingga karyawan harus mampu memahami kebijakan yang berubah ini juga mendorong agar perusahaan mampu survive dengan perubahan era globalisasi.

Sebagai karyawan haruslah mengikuti aturan yang sudah ditetapkan. Setiap karyawan memiliki tujuan dan permasalahan dalam bekerja berbeda-beda. Kecocokan nilai individu dengan perusahaan merupakan salah satu kunci terjadi hubungan yang harmonis antara karyawan dan perusahaan. Pada kenyataannya masih ada karyawan yang belum mampu menerima nilai-nilai organisasi dalam perusahaan seperti tidak disiplin waktu kerja, masih sering terjadinya pelanggaran, pemborosan terhadap perlatan kerja, keinginan mendapatkan promosi jabatan tanpa disertai dengan peningkatan prestasi kerja dan permasalahan ketidakcocokan antara keinginan dan perilaku karyawan dan perusahaan. Dari berbagai penyimpangan tentu akan berdampak pada menurunnya komitmen karyawan terhadap organisasi perusahaan.

Selain itu yang dilakukan dalam mempertahankan karyawan ialah dengan terus meningkatkan komitmen organisasi. Komitmen organisasi ialah kekuatan yang bersifat relatif dari individu dalam mengidentifikasi keterlibatannya ke perusahaan (Rumangkit \& Haholongan, 2019). Komitmen organisasi sangat penting bagi perusahaan agar karyawan 
mampu memberikan kontribusi secara maksimal ke perusahaan. Komitmen organisasi merupakan identifikasi rasa, keterlibatan dan loyalitas yang ditunjukkan karyawan terhadap perusahaan yang menjadi tempat untuk mengabdi dan bekerja didukung oleh penelitian (Priansa, 2016). Komitmen organisasi yang tinggi pada karyawan menjadikan karyawan peduli dengan nasib organisasi dan berusaha menjadi organisasi yang lebih baik, sehingga adanya komitmen tinggi mendukung terhindarnya kesenjangan yang dapat dihindari. Sebaliknya jika karyawan dengan komitmen rendah lebih akan mementingkan dirinya atau kelompoknya. Dia tidak memiliki keinginan untuk menjadikan organisasi ke arah yang lebih baik penelitian ini didukung oleh Hidayat (2014). Salah satu dampak positif dari karyawan tetap yang berkomitmen dapat ditunjukkan masa kerja di organisasi.

Karyawan yang berkomitmen memiliki kesesuaian tujuan dan keterlibatan dalam organisasi, sehingga karyawan merasa nyaman dan lebih memilih tetap tinggal diperusahaan tanpa ada paksaan dari pihak internal maupun eksternal. Penelitian ini didukung oleh Sumanto (2016) yang mendifinisikan komitmen organisasi ialah kuatnya pengenalan dan keterlibatan seseorang dalam suatu organisasi. Komitmen karyawan sangat diperlukan bagi perusahaan agar memudahkan untuk mengendalikan dan mengelola sumber daya manusia yang ada dengan maksimal. Komitmen karyawan terhadap organisasi merupakan modal untuk perusahaan dapat menjamin keberlangsungan operasional perusahaan. Dengan adanya komitmen karyawan diharapkan karyawan memiliki loyalitas yang tinggi dengan perusahaan (Sabbato, 2020).

Dalam hal karyawan berkomitmen juga ada pengaruh dengan person organization fit dengan kesesuaian antara nilai organisasi dengan nilai individu karena kesesuaian ini muncul dari person organization fit. Person organization fit sangat dibutuhkan dalam menjaga keberlangsungan karyawan pada perusahaan, apabila karyawan tidak merasakan kesesuaian antara nilai karyawan dengan perusahaan maka karyawan bisa merasakan ketidaknyamanan dan menimbulkan keputusan untuk resign dari perusahaan. Tujuan dari adanya Person organization fit agar karyawan merasakan tujuan nilai yang sama dengan perusahaan (Rumangkit \& Haholongan, 2019).

Dalam hal ini komitemn dan person organization fit akan memberikan dampak kepuasan kerja, yang memberikan penilaian dari pekerja yaitu seberapa jauh pekerjaannya dirasakan dapat memuaskan kebutuhannya. As'ad (1984) kepuasan kerja didefinisikan sebagai perasaan seseorang terhadap pekerjaan, dimana perasaan ini merupakan refleksi dari perilaku seseorang terhadap pekerjaannya apakah merasa nyaman atau tidak saat bekerja. 
Jika karyawan memiliki kepuasan dalam bekerja, karyawan akan cenderung berkomitmen terhadap organisasi tempatnya bekerja. Chan (2006), dalam penelitiannya menemukan bahwa komitmen yang tinggi dari anggota kelompok akan memberikan energi dan memotivasi mereka untuk bekerja lebih baik. Anggota yang berkomitmen tinggi akan saling menerima, belajar dari anggota yang lain dan berpartisipasi penuh dalam setiap kegiatan organisasi. Saat karyawan mampu berkomitmen penuh dengan perusahaan maka karyawan secara sosial juga merasa nyaman dari segi lingkungan sosial pertemanan juga mendukung walaupun dari segi pekerjaan berat. Dari sisi sosial sangat berpengaruh untuk mendukung karena secara tidak langsung beban pekerjaan itu akan teralihkan dengan kepuasaan kerja dan juga konsep sosial yang sudah terkonsep nyaman untuk karyawan. Karyawan yang sudah mempunyai komitmen tinggi pada perusahaan maka akan memberikan dampak pada perusahaan yang sehat dan kultur budaya mampu diterima oleh seluruh karyawan. Secara tidak langsung keterikan emosional pada seluruh karyawan yang berada diperusahaan akan memberikan kepuasan kerja pada karyawan, serta keterlibatan keterikan emosional juga akan mendorong untuk karyawan mampu belajar dan kesempatan untuk upgrade menjadi lebih baik. Karyawan yang mempunyai komitemen tinggi juga akan memberikan dampak pada kesuaian karyawan terhadap nilai-nilai serta budaya organisasi yang ada diperusahaan.

\section{METODE}

Pendekatan yang digunakan dalam penelitian ini adalah pendekatan kualitatif dengan pendekatan Studi Pustaka dan teknik pengumpulan data observasi online dan dokumenter, sedangkan teknik analisis datanya menggunakan analisis isi (content analysis). Jenis data yang digunakan yaitu berupa data sekunder. Penelitian dilakukan dengan mengidentifikasi berkaitan dengan kepribadian manusia dilihat dari perspektif psikologi dan filsafat, selanjutnya data dikumpulkan, dianalisis dan disimpulkan sesuai kebutuhan, dan dikembangkan dengan menggunakan studi kepustakaan. Berdasarkan dari metode peneliti yang di atas, maka peneliti mencari dokumentasi penelitian sebelumnya berkaitan dengan komitmen organisasi dan person-organization fit.

\section{HASIL}

Menurut penelitian dari Bangun \& Supartha \& Subudi, (2017) bahwa ada kesesuaian antara seseorang dengan pekerjaan yang akan mempengaruhi komitmen organisasi yang dimiliki karyawan. Bahwa person organization fit memiliki pengaruh lebih besar bila adanya 
peran komitmen organisasi pada karyawa. Menurut penelitian Yuniawan \& Maria, (2016) bahwa Person-Organization Fit memiliki pengaruh kecil yang positif dan signifikan terhadap kinerja karyawan, sehingga besarnya tingkat Person Organization Fit (P-O Fit) yang tinggi dapat meningkatkan kinerja karyawan. Indikator P-O Fit yang paling berpengaruh terhadap kinerja karyawan adalah kesesuaian tujuan, karena kesesuaian tujuan. Menurut Sudaryanto \& Rijanti (2017) bahwa Person Organization Fit (PO-Fit) berpengaruh positif terhadap Komitmen Organisasional yang berarti bahwa Person Organization Fit (PO-Fit) (kesesuaian nilai, kesesuaian tujuan, pemenuhan kebutuhan karyawan, kesesuaian budaya kepribadian) yang tinggi akan menghasilkan kesesuaian nilai nilai individu dengan nilai-nilai organisasi yang tinggi pada Komitmen Organisasional (komitmen avektif, komitmen normatif dan komitmen berkelanjutan).

Menurut Astuti, 2010 bahwa ada hubungan positif antara Person Organization Fit dengan kinerja yang merupakan employee outcomes dengan kepuasan kerja, komitmen organisasional. Penelitian ini mendukung hasil penelitian sebelumnya yang dilakukan oleh Mete, Alptekin, \& Yunus (2016), hasil penelitiannya menunjukkan bahwa komitmen organisasi terhadap karyawan akan meningkat, kepuasan kerja dan person-organization fit karyawan memberikan signifikansi kenaikan. Menurut Nazir dan Saima (2014) ada hubungan yang positif dan signifikan antara hubungan person-organization fit dengan komitmen organisasi. Khaola dan Sebotsa (2015) dari penelitiannya bahwa ada hubungan yang positif dan signifikan antara person-organization fit dan komitmen organisasi; personorganization fit dan OCB; komitmen organisasi dan OCB. Penelitian Hueryren (2012) bahwa karyawan akan memberikan kesediaanya untuk tinggal dan mengabdikan agar mencapai tujuan pekerjaan karena mereka memiliki nilai yang sama dan tujuan organisasi. Seorang karyawan yang memiliki komitmen organisasi, produktifitas mereka akan meningkat dan begitu juga prestasi kerja.

\section{PEMBAHASAN}

Menurut Mc. Shane dan Von Glinow (dalam Rumangkit \& Haholongan, 2019) komitmen organisasi ialah keterikatan emosional karyawan pada organisasi, mengidentifikasikan diri dengan organisasi dan keterlibatan karyawan pada organisasi. Tenaga kerja yang berkomitmen merupakan keunggulan kompetitif untuk perusahaan. Keunggulan kompetitif karyawan dengan masa kerja yang semakin lama mempunyai 
pengetahuan yang lebih baik dan mendalam serta para relasi lebih menyukai untuk bekerjasama dengan karyawan yang sudah dikenal.

Komitmen organisasional merupakan dimensi perilaku yang penting dan dapat digunakan untuk mengevaluasi seberapa besar dedikasi karyawan pada organisasi. Pada dasarnya, faktor pribadi maupun faktor organisasi sama-sama memiliki pengaruh terhadap komitmen. Seorang karyawan memiliki komitmen pada organisasi berarti karyawan, memiliki identitas diri yang kuat pada organisasi, menerima sistem nilainya, bersedia untuk bertahan dan mau bekerja dengan sungguh-sungguh demi organisasi. Selain menerima sistem nilainya, karyawan dengan komitmen tinggi juga akan memberikan segala usaha, kemampuan dan loyalitasnya untuk mewujudkan nilai dan tujuan organisasi tersebut.

Aspek komitmen karyawan pada organisasi, Menurut Allen dan Mayer (dalam Sabbato, 2020) dibagi menjadi tiga dimensi, yaitu:

\section{a. Affective commitment}

Keterikatan emosional, identifikasi serta keterlibatan seorang karyawan pada suatu organisasi. Komitmen afektif seseorang akan menjadi lebih kuat bila pengalamannya dalam organisasi konsisten dengan harapan-harapan dan memuaskan kebutuhan dasarnya dan sebaliknya. Komitmen dipengaruhi apabila keterlibatan dalam organisasi terbukti menjadi pengalaman yang memuaskan yaitu dapat memeberikan kesempatan untuk melakukan pekerjaan dengan memuaskan atau menghasilkan kesempatan untuk menghasilkan skill.

\section{b. Continuance Commitment}

Komitmen yang didasarkan pada kerugian bagi karyawan bila meninggalkan organisasi. Hal ini dapat dijelaskan bahwa continuance commitment dipengaruhi dan pada saat individu melakukan investasi, yang mana investasi tersebut akan hilang atau berkurang nilainya apabila individu beralih dari organisasinya. Komitmen ini berhubungan dengan pendekatan side-bets sisi pertaruhan yang menunjukkan kuatnya tendensi kebutuhan seseorang untuk terus bekerja bagi organisasi. Konsep side-bets orientation, menekankan pada sumbangan seseorang sewaktu-waktu dapat hilang jika orang itu meninggalkan organisasi. Tindakan meninggalkan organisasi menjadi suatu yang beresiko tinggi karena orang merasa takut akan kehilangan sumbangan yang mereka tanamkan pada organisasi itu dan menyadari bahwa mereka tidak mungkin mencari penggantinya. Karyawan dengan komitmen berkelanjutan 
yang kuat akan tetap tinggal karena mereka merasa bahwa membutuhkan organisasi dan cenderung menghindari kerugian finansial.

c. Normative commitment

Jaminan yang dirasakan untuk tetap tinggal di organisasi. Komitmen normatif dipengaruhi dari internalisasi tekanan normatif untuk melakukan serangkaian tindakan tertentu dan penerimaan keuntungan yang menimbulkan perasaan akan kewajiban yang harus dibalas. Karyawan merasa wajib untuk tetap tinggal dalam suatu organisasi karena adanya perasaan hutang budi pada organisasi sehingga mereka mempunyai kewajiban moral untuk melakukan kewajiban timbal balik pada organisasi tempat meraka bekerja. Karyawan dengan komitmen normatif yang kuat akan tetap tinggal karena mereka seharusnya melakukan hal tersebut sebagai balasan atas apa yang telah diterimanya dari organisasi.

Menurut Mc-Culloch dan Turban (2007) melihat person-organization fit sebagai kesamaan nilai, kesamaan tujuan, dan kes-esuaian antara kebutuhan karyawan dan dukungan yang terdapat di lingkungan kerja, kesesuaian antara karakteristik individu dan organisasi. Kesesuaian yang terjadi dimulai ketika proses seleksi karyawan dimulai. Pencari kerja akan tertarik pada organisasi yang memiliki kesamaan dengan karakteristik pribadi yang mereka miliki. Menurut (Morley, 2007) menyatakan bahwa person-organization fit menekankan pada pentingnya kesesuaian antara karyawan dan proses pekerjaan serta menciptakan identitas organisasi melalui nilai-nilai yang terdapat pada budaya suatu organisasi.

Person-organization fit menekankan sejauh mana seseorang dan organisasi memiliki karakteristik yang sama dalam memenuhi kebutuhan masing-masing (Sekiguchi, 2004). Salah satu peran penting dalam manajemen sumber daya manusia adalah menetapkan penarikan, seleksi, dan penempatan karyawan berdasarkan asas "the rightman in the right place anda the right man in the right job" (Hasibuan, 2012). Person-organization fit dapat dilihat melalui proses setelah perubahan organisasi dimana secara garis besar perubahan organisasi dapat diamati melalui tujuan organisasi, perubahan nilai-nilai yang dianut perusahaan dan iklim organisasi. Dibuktikan dengan penelitian yang dilakukan oleh Asti (2010) dan Tania, Sutanto (2013) menyatakan bahwa komitmen organisasi dipengaruhi oleh person organization.

Aspek-aspek person-organization fit menurut beberapa peneliti. Kristof (1996) membagi person-organization fit menjadi empat aspek : 
a. Kesesuaian antara nilai atau prinsip individu dan organisasi (value congruence) ialah kesesuaian antara nilai instrinsik individu dengan organisasi.

b. Kesesuaian antara tujuan individu dengan organisasi (goal congruence) ialah kesesuaian tujuan individu dengan organisasi dalam hal ini ialah pemimpin dan rekan kerja.

c. Kesesuaian antara kebutuhan karyawan dan dukungan yang terdapat dalam lingkungan kerja dan struktur organisasi (employee need fulfillment) ialah kesesuaian kebutuhan karyawan dan kekuatan yang terdapat dalam lingkungan kerja dengan sistem dan struktur oganisasi.

d. Kesesuaian antara karakteristik individu dan organisasi (culture personality congruence) ialah kesesuaian kepribadian dari individu dan kultur organisasi yang ada.

Kesesuaian karakteristik ini mengacu pada kesesuaian pengetahuan, keahlian dan kemampuan yang dimiliki oleh karyawan terhadap kebutuhan perusahaan. Person organization fit dapat mempengaruhi tingkat komitmen organisasional karyawan. Hal didukung dengan penelitian yang dilakukan oleh (Sugianto, 2012) yang menyatakan bahwa karyawan yang memiliki kesesuaian dengan organisasi akan terus berada didalam organisasi sampai jangka waktu yang lama. Karena semakin merasakan kesesuaian pribadi dengan organisasi maka dengan sendirinya tingkat komitmen organisasional karyawan akan meningkat dan akan bekerja secara optimal di dalam organisasi serta tidak akan memiliki rasa untuk pergi dari perusahaan.

Keterikatan emosional seseorang pada organisasi akan memberikan pengaruh pada kenyaman kerja, kepuasan kerja yang berdampak pada komitmen karyawan pada organisasi, yang bisa dikatakan karyawan yang loyal juga sesuai dengan nilai atau prinsip individu dengan organisasi. Karyawan yang meninggalkan organisasi juga akan mengalami kerugian seperti finansial sehingga karyawan yang tetap komitmen dengan perusahaan juga aan dipengaruhi oleh tekanan normatik yang menimbulkan rasa untung seperti ada jaminan yang diberikan perusahaan kepada karyawan. Selain jaminan dari person organization fit memberikan kesesuaian kebutuhan karyawan yang didukung dengan lingkungan sosial kerja yang mendukung dan memberikan kenyaman. Secara kultur budaya juga akan mempengaruhi kenyaman komitmen karyawan untuk perusahaan. 


\section{SIMPULAN}

Berdasarkan deskripsi mengenai komitmen organisasi dan person fit organization diatas maka dapat disimpulkan bahwa ketidaksesuaian karyawan dengan perusahaan akan menimbulkan dampak karyawan untuk resign dan ketidaknyamanan dalam budaya organisasi. Saat kesesuaian tercipta dalam budaya organisasi sudah terbentuk maka komitmen organisasi juga akan terbentuk dalam emosional seorang karyawan. Sehingga yang paling dominan berpengaruh ialah komitmen organisasi karyawan. Kecocokan ini menciptakan lingkungan kerja yang nyaman dan keselamatan kerja yang tinggi memberikan peningkatan kinerja dengan berdampak pada efektifitas kerja. Faktor-faktor yang memperngaruhi komiten organisasi ini ialah kesesuaian nilai-nilai, kebijakan atau peraturan serta budaya organisasi. Individu merasa ada kesesuaian dengan perusahaan ketika emosional individu sudah terikat dengan organisasi. Komitmen ini berhubungan dengan pendekatan side-bets sisi pertaruhan yang menunjukkan kuatnya tendensi kebutuhan seseorang untuk terus bekerja bagi organisasi. Dan individu juga merasa terjamin kehidupannya sehingga individu merasa wajib untuk tinggal. Dalam ini ada pengaruh yang cukup kuat yaitu kesesuaian karakter, nilai-nilai, tujuan organisasi dan individu, serta kesesuaian struktur organisasi. Oleh karena itu sangat penting untuk memahami faktor-faktor yang mendorong agar karyawan atau individu tetap bertahan.

\section{DAFTAR RUJUKAN}

As'ad, Moh. (2008). Seri Ilmu Sumber Daya Manusia: Psikologi Industri (Edisi keempat). Yogyakarta: Liberty.

Astuti, S, D. (2010). Model Person Organization Fit (P-O Fit Model) Terhadap Kepuasan Kerja, Komitmen Organisasional Dan Kinerja Karyawan. Jurnal Bisnis dan Ekonomi, 17(1). 58. https://media.neliti.com/media/publications/24269-ID-model-personorganization-fit-p-o-fit-model-terhadap-kepuasan-kerja-komitmen-org.pdf

Bangun \& Supartha \& Subudi. (2017). Pengaruh Person-Job Fit Dan Person-Organization Fit Terhadap Komitmen Organisasional Dan Organizational Citizenship Behavior (OCB). Jurnal Ekonomi Bisnis Udayana, 6(5). 2088-2099. Https://Ojs.Unud.Ac.Id/Index.Php/EEB/Article/View/29794

Hueryren, Y., \& Dachuan, H. (2012). The Mediating Effect of Organizational Commitment on Leadership Type and Job Performance. The Journal of Human Resource and Adult Learning, 8, 50-59.

Khaola, P. P., \& Thotaone, S. (2015). Person-organization fit, Organizational commitment and organisational citizenship Behaviour. Danish Journal of Management and Business Sciences, 1, 67-74.

Mete, E. S., Alptekin, S. \& Yunus, B. (2016). The Relationship between Organizational Commitment, Organizational Indentification, Person-Organization Fit and Job Satisfaction : A Research on IT Employees. International Review of Management and Business Research, 5, 67-74. 
Nazir, A. N., \& Saima. (2014). Person-Organization fit and Organizational Outcome Variables: A Review. International Journal of Business and Management Invention, 3, (7), 54-58.

Octaviani, H \& Hartijasti, Y. (2016). Pengaruh Person Organization Fit Dan Budaya Organisasi Terhadap Turnover Intention Dengan Kepuasan Kerja Sebagai Variabel Mediator : Analisis Pada Karyawan Generasi Y Di PT X, PT Y Dan PT Z. Jurnal Manajemen Indonesia, 16(1), 4. https://doi.org/10.25124/jmi.v16i1.723

Rumangkit, S \& Haholongan, J. (2019). Person Organization Fit, Motivasi Kerja, Dan Kepuasaan Kerja Terhadap Komitmen Organisasional. Jurnal Technobiz, 3(4), 19-23. https://doi.org/10.33365/tb.v3i2.449

Rumangkit, S \& Maryati, S. (2017). Pengaruh Person-Organization Fit Terhadap Komitmen Organisasional Melalui Kepuasaan Kerja Pada Karyawan Ibi Darmajaya. Jurnal Ekonomi \& Pengembangan Optimum, 7(2), 191-199. http://dx.doi.org/10.12928/optimum.v7i2.7918

Sabbato, K. (2020). Pengaruh Person Organiztion Fit Terhadap Komitmen Karyawan Pada PT Kahala Citra Indonesia. Jurnal Riset Entrepreneurship, 3(2), 80-87. http://dx.doi.org/10.30587/jre.v3i2.1476

Sudaryanto \& Rijanti. (2017). Pengaruh Kompetensi Dan Person Organization Fit (Po-Fit) Terhadap Kinerja Melalui Mediasi Komitmen Organisasional Studi Pada Penyuluh Pertanian Dinas Pertanian Tanaman Pangan Dan Peternakan Kabupaten Pati. Jurnal Manajemen, $14(2)$ 188-199. https://www.onesearch.id/Record/IOS1491.article7903? widget $=1$ \&repository $\mathrm{id}=3599$

Yuniawan \& Maria. (2016). Analisis Pengaruh Person-Organization Fit TerhadapvKinerja Karyawan: Komitmen Organisasional Dan Organizational Citizenship Behaviour Sebagai Variabel Intervening (Studi Pada Karyawan PT Telkom Witel Pekalongan). Jurnal Undip $5(1)$, 11. https://ejournal3.undip.ac.id/index.php/djom/article/view/13441/12997 